\title{
1 INTERMEDIUM-C mediates the shade-induced bud growth arrest in barley
}

2

3 Hongwen Wang ${ }^{1,2, *}$, Christiane Seiler $^{2}$, Nese Sreenivasulu ${ }^{3}$, Nicolaus von Wirén ${ }^{1, *}$ and Markus

$4 \quad$ Kuhlmann ${ }^{2, *}$

5

$6 \quad{ }^{1}$ Department of Physiology and Cell Biology, Leibniz Institute of Plant Genetics and Crop Plant

7 Research (IPK) Gatersleben, Corrensstrasse 3, 06466 Stadt Seeland, Germany

$8 \quad{ }^{2}$ Department of Molecular Genetics, Leibniz Institute of Plant Genetics and Crop Plant Research (IPK)

9 Gatersleben, Corrensstrasse 3, 06466 Stadt Seeland, Germany

$10{ }^{3}$ International Rice Research Institute (IRRI), Grain Quality and Nutrition Center, Metro Manila, 11 Philippines

Running title: Genetic control of shade-induced bud growth arrest

Correspondence to: Hongwen Wang (email: wangh@ipk-gatersleben.de), Nicolaus von Wirén (email: vonwiren@ipk-gatersleben.de) and Markus Kuhlmann (email: Kuhlmann@ipkgatersleben.de)

Tel: $+49-0394825-172$ or $+49-0394825-602$

Fax: $+49-0394825-550$

Department of Molecular Genetics \&

Department of Physiology and Cell Biology

Leibniz Institute of Plant Genetics and Crop Plant Research (IPK)

Gatersleben, Corrensstrasse 3

06466 Stadt Seeland, Germany

The authors responsible for the distribution of materials integral to the findings presented in this article in accordance with the policy described in the instructions for authors are Hongwen Wang (wangh@ipk-gatersleben.de), Nicolaus von Wirén (vonwiren@ipkgatersleben.de) and Markus Kuhlmann (Kuhlmann@ipk-gatersleben.de). 


\section{Abstract}

Tiller formation is a key agronomic determinant for grain yield in cereal crops. The modulation of this trait is controlled by transcriptional regulators and plant hormones, tightly regulated by external environmental conditions. While endogenous (genetics) and exogenous (environmental factors) triggers for tiller formation have mostly been investigated separately, 43 it has remained elusive how they are integrated into the developmental program of this trait. 44 The transcription factor INTERMEDIUM-C (INT-C), which is the barley ortholog of the maize domestication gene TEOSINTE BRANCHED1 (TB1) has a prominent role in regulating tiller bud outgrowth. Here we show that $I N T-C$ is expressed in tiller buds, required for bud growth arrest in response to shade. In contrast to wild type plants, int-c mutant plants are impaired in their shade response and do not stop tiller production after shading. Gene expression levels of INT-C are up-regulated under light-limiting growth conditions, and down-regulated after decapitation. Transcriptome analysis of wild-type and int-c buds under control and shading conditions identified target genes of INT-C that belong to auxin and gibberellin biosynthesis and signaling pathways. Our study identifies INT-C as integrator of the shade response into tiller formation, which is prerequisite for implementing shading responses in the breeding of cereal crops.

Key words: INTERMEDIUM-C, yield, barley, bud growth arrest, shade avoidance, decapitation, abscisic acid 


\section{Introduction}

72

Ensuring yield stability of cereal crops is a major requirement for plant breeding in the face of climate change (Kang et al., 2009). In particular, breeding of new elite varieties with optimized shoot architecture, such as tiller number, will allow maintaining high yield potential in unfavorable environments. In many countries, particularly at very high latitudes or on shaded slopes, light is a limiting factor affecting crop growth and yield. Moreover, during the past decades intensive crop management has increased sowing and plant stand densities to improve homogeneity among individual plants that now produce less tillers. To increase light capture, plants have evolved refined mechanisms to maximize light harvesting and/or to prevent shade, i.e. low light intensity and/or a low ratio of red (R) to far-red (FR) light. Suboptimal light triggers a suite of phenotypic changes, defined as the shade avoidance response (SAR) that includes hypocotyl and petiole elongation, an upward orientation of leaves and early flowering. Additionally, a common characteristic of SAR is the suppression of shoot branching in a wide variety of species (Smith and Jordan, 1994; Tucic et al., 2006; Aguilar-Martinez et al., 2007; Gonzalez-Grandio et al., 2013).

The extensive work carried out in Arabidopsis has provided a detailed understanding of the SAR (Wang and Wang, 2015). By sensing and responding to $R$ and FR light, the five photoreceptors of the phytochrome family (phyA-phyE) regulate a variety of developmental processes (Franklin and Quail, 2010). Among these, phytochrome B (phyB) appears to be the most important photoreceptor involved in shade detection and avoidance (Reed et al., 1993; Ballare, 1999), functioning redundantly with other members of its clade (Stamm and Kumar, 2010). Phytochrome proteins act as dimers and exist in two photo-convertible forms: 'Pr' (the red-light-absorbing, inactive form) and 'Pfr' (the far-red-light-absorbing, active form), with the Pfr:Pr ratio reflecting the R:FR ratio of the environment (Smith, 2000). Upon photoconversion into active Pfr, phytochromes migrate to the nucleus, where they regulate gene expression by interacting with several basic helix-loop-helix (bHLH) transcription factors, including phytochrome interacting factor (PIF) and PIF-like (PIL) proteins (Chen et al., 2004; Duek and Fankhauser, 2005). In many plant species, genome-wide transcriptional dynamics of the SAR have been studied in petioles or leaf blades at the seedling stage, while SAR is less defined in economically important monocots (Devlin et al., 2003; Tao et al., 2008; Hornitschek et al., 2012; Wang et al., 2016). 
103 In the agricultural production of graminaceous crop species, plant density is a major determinant for crop yield. Shading caused by elevated plant densities reduces not only photosynthetic active radiation (PAR) flux density but also the R/FR ratio of the light reaching the lower strata of the canopy. Generally, increasing plant density results in progressively stronger suppression of tillering due to accelerated apical shoot development and stem elongation. This pattern continues until the beginning of the stem elongation phase (Zadoks, 1985). Moreover, early-emerging tillers contribute more to grain yield than do tillers that emerge later. The regulation of barley tiller outgrowth by shade has also been supported by the observation that supplemental FR illumination of elongating leaves or of the main stem base reduced the total number of tillers per plant (Skinner and Simmons, 1993). In spite of its great ecological and economic impact, little is known about the underlying molecular mechanisms linking shade-initiated transcriptional changes with the suppression of tiller outgrowth in barley plants, especially regarding the tiller bud that is one of the most important sites of shade action.

Lateral shoot growth is coordinately controlled by conserved interactions that regulate the biosynthesis and signaling of the hormones auxin, abscisic acid (ABA), strigolactones (SL), and cytokinins (CK). Auxin and SL, synthesized mainly in the shoot apex and root, respectively, inhibit branching, while CK, synthesized mostly in the root and stem, promote branching (Kebrom et al., 2013; Wang et al., 2018).

The class II TEOSINTE BRANCHED1, CYCLOIDEA, and PCF (TCP) transcription factors TEOSINTE BRANCHED 1 (TB1)-like, in monocots, and BRANCHED1 (BRC1)-like, in dicots, act locally inside the axillary bud where they are subject to transcriptional regulation by hormonal cross-talk (auxin-SL-CK) and cause bud growth arrest (Doebley et al., 1997; Aguilar-Martinez et al., 2007; Minakuchi et al., 2010; Martin-Trillo et al., 2011; Braun et al., 2012). Moreover, recent studies have implicated the involvement of TB1 orthologs in the shade-induced response of branch suppression. In Sorghum bicolor and maize, active phyB (Pfr) suppresses the expression of the $T B 1$ gene and induces bud outgrowth. On the other hand, light signals that inactivate phyB allow increased expression of $T B 1$ and suppression of bud outgrowth (Kebrom et al., 2006; Kebrom et al., 2010; Whipple et al., 2011). In Arabidopsis, BRCl is upregulated in axillary buds of plants grown at high density and is required for complete branch suppression in these conditions (Aguilar-Martinez et al., 2007). These results suggest that the phytochrome pathway is involved in the control of TB1 and axillary meristem outgrowth, and provides a link between environmental variation and gene action controlling branching. In barley, INT-C is an ortholog of the maize domestication gene 
$137 T B 1$, and its mutants exhibit higher tiller numbers and enlarged lateral spikelets (Ramsay et 138 al., 2011).

Here, we investigated the shade avoidance response of early formed tiller buds in barley plants before the rapid stem elongation stage, and studied the role of INT-C during the SAR by comparable transcriptome analysis. The analysis revealed that the dynamics of INT-C expression during SAR is critical for genome-wide reprogramming of gene expression and that the gene categories affected support a central role of INT-C in tiller bud arrest. A comparison of genes responding to shade-induced bud arrest and decapitation-triggered bud activation allowed us to identify key regulators influencing bud dormancy and bud activation genes. Thus, these findings would enable us to better understand the genetic mechanisms controlling the reversible transition of growth to dormancy in barley tiller buds.

\section{Materials and Methods}

Plant material and growth conditions. Hordeum vulgare cv. Bowman, a two-rowed spring barley cultivar, was used as wild type for comparison to its near isogenic mutant BW421 (intc.5) (Ramsay et al., 2011). For the experimental analyses except the shading experiment, wild type and int-c mutant plants were cultivated in a greenhouse. Seeds were sown in either 54 or 96 well trays and germinated in a climate chamber for 10 days at $11^{\circ} \mathrm{C}$ day and $7^{\circ} \mathrm{C}$ night temperature under $16 \mathrm{~h}$ light. After that, seedlings were transferred to pots (diameter $16 \mathrm{~cm}$ ) filled with 2 parts of compost, 2 parts of "Substrat 2" (Klasmann) and 1 part of quartz sand, and allowed to grow in the greenhouse at $20^{\circ} \mathrm{C}$ day $/ 14^{\circ} \mathrm{C}$ night under $16 \mathrm{~h}$ light. For the density experiments, three barley planting densities $\left(1,5,10\right.$ plants pot $\left.^{-1}\right)$ were established in pots (size: 21-liter, top diameter: $310 \mathrm{~cm}$, base diameter: $250 \mathrm{~cm}$, height: $214 \mathrm{~cm}$ ), and the planting density test was repeated four times. For the decapitation experiments, when plants were grown till the early stem elongation stage, the shoot apices were removed, and the apical dominance test was repeated three times. For the shading experiments, seedlings were grown in a climate-controlled growth chamber at a temperature of $12^{\circ} \mathrm{C}, 70 \%$ humidity and a $12 / 12 \mathrm{~h}$ day/night cycle. Green shading was achieved by using a green plastic filter (122 Fern Green;

Sequence retrieval for TCP proteins. In order to identify barley genes putatively encoding 
171 http://webblast.ipk-gatersleben.de/barley/viroblast.php was searched using the TBLASTN 172 algorithm with Arabidopsis TCP proteins or TCP domains as query sequence. All redundant sequences were discarded from further analysis based on ClusterW (Thompson et al., 1994).

174 Furthermore, to verify the reliability of the initial results, all non-redundant candidate TCP sequences were analyzed to confirm the presence of the conserved TCP domain using the InterproScan program (Quevillon et al., 2005). The sequences of TCP family members in the genome of Arabidopsis were retrieved from the PlantTFDB plant transcription factor database (http://planttfdb.cbi.pku.edu.cn/, v3.0). As for Antirrhinum majus and Oryza sativa TCP sequences, they were obtained from NCBI.

Phylogenetic analysis. Multiple sequence alignments were conducted on the amino acid sequences of TCP proteins in Arabidopsis and barley genomes using Cluster X (Thompson et al., 1997) with default settings. Subsequently, MEGA 6.0 software (Tamura et al., 2013) was employed to construct an unrooted phylogenetic tree based on alignments using the NeighborJoining (NJ) method with the following parameters: JTT model, pairwise gap deletion and 1,000 bootstraps.

Extraction and quantification of ABA. ABA was extracted from fresh plant materials using ethyl acetate (100\%). Isotopically labelled D6-ABA was used as an internal standard and added to each sample during the extraction procedure. Extraction was carried out twice with 1 $\mathrm{ml}$ of ethyl acetate at $4^{\circ} \mathrm{C}$. The supernatant collected after centrifugation $(13.000 \mathrm{~g}, 10 \mathrm{~min}$, and $4{ }^{\circ} \mathrm{C}$ ) was evaporated to dryness at room temperature using a vacuum concentrator. The dried samples were dissolved in acetonitrile: methanol (1:1) and filtered using a $0.8 \mu \mathrm{m}$ filter (Vivaclear). The filtrate $(10 \mu \mathrm{L})$ was used for subsequent quantification by LC-MS/MS (Dionex Summit coupled to Varian 1200 L). Chromatographic separation was carried out on a C18 column ( $4 \mu \mathrm{m}, 100 \mathrm{~mm}$; GENESIS; Vydac/USA). MRM and quantification was done using the mass traces $263 / 153$ for $\mathrm{ABA}$ and 269/159 for D6-ABA. The validity of the extraction and measurement procedure was verified in recovery experiments (approx. 8295\%). Quantification was based on calibration with known ABA standards and individual recovery rates for the samples, as described in (Kong et al., 2008).

201 plant tissues from independent or pooled biological replicates with the same treatment using a 
205

206

207

208

209

210

211

212

213

214

215

216

217

218

219

220

221

222

223

224

225

226

227

228

229

230

231

232

233

234

235

236

237

quality and quantity assessed with a Nano drop device (Peqlab, Erlangen, Germany). A 500ng aliquot was taken as template for the synthesis of the first cDNA strand, primed by oligo(dT), using a RevertAid cDNA kit (ThermoFisher SCIENTIFIC, Waltham, MA, USA). The subsequent qRT-PCR was based on the Power SYBR ${ }^{\circledR}$ Green PCR Master Mix (ThermoFisher SCIENTIFIC) and conducted in an Applied Biosystems 7900HT Fast RealTime PCR system (ThermoFisher SCIENTIFIC) following the manufacturer's protocol. Relative transcript abundances were obtained using $\Delta \Delta \mathrm{C}_{\mathrm{T}}$ method (Livak and Schmittgen, 2001) and were normalized against the abundance of serine/threonine phosphatase PP2A transcript. The primer sequences employed are given in Supplemental Table S6. The presence of a unique PCR product was verified by dissociation analysis and each qRT-PCR was repeated at least three times. Each biological replicate was represented by three technical replicates.

For the microarray procedure, the same RNA samples extracted from three biological replicates was used and the quality of the RNA was verified with a Bioanalyzer 2100 device (Agilent Technologies, Santa Clara, CA, USA). The RNA was labeled by using the Low input QuickAmp Labeling kit (Agilent Technologies) and hybridized, following the manufacturer's protocol, to a custom-synthesized $60 \mathrm{k}$ Barley Microarray (Agilent Technologies) (Koppolu et al., 2013). The resulting data were analysed using GeneSpring 13.0 GX software (Agilent Technologies). After quantile normalization and baseline transformation to the median of all samples, the probesets (genes) were filtered by Coefficient of Variation $<50 \%$, followed by moderated T-Test and Bonferroni-Holm multiple testing corrections. Probesets passing the Pvalue cut-off $<0.05$ with a fold change of $\geq 2.0$ were selected as differentially expressed genes (DEG). Analyses of functional categories with INT-C-dependent upregulated and downregulated genes were performed using MapMan. The fold enrichment was calculated as follows: (number in class input_set/number of total input_set)/ (number in class reference_set/ number of total reference_set). The $P$ value was determined by a hypergeometric distribution test (R Core Team, 2013). The data was sorted by fold enrichment with a cut-off of $P<0.05$. For the specific pathway enrichment analysis by Wilcoxon-Rank-Sum test was implemented in MapMan. The resulting enrichments for the functional classes $(\mathrm{p}<0.05$, determined by a hypergeometric test; R Core Team, 2013) provided a map of gene modules regulated in dependence of INT-C during SAR. To confirm that the common genes of the two identified groups are not by random, the test of statistical significance was applied by a web-based tool at http://nemates.org/MA/progs/overlap_stats.html. The co-regulated genes were retrieved 
238

239

240

241

242

243

244

245

246

247

248

249

250

251

252

253

254

255

256

257

258

259

260

261

262

263

264

265

266

267

268

269

270

271

from Genevestigator (Zimmermann et al., 2004), and Gene Ontology analysis was performed in agriGO v2.0 with default parameters (Tian et al., 2017).

Statistical analysis. To test the statistical significance of the data, Student's $t$ test and oneway analysis of variance (ANOVA) with Tukey test for significance were used. Asterisks denote significant differences in Student's $t$ tests. Different letters denote significant differences in Tukey's test.

\section{Results}

\section{$I N T-C$ is a member of the barley TCP gene family}

INTERMEDIUM- $\underline{C}$ (INT-C) is the barley orthologue of TEOSINTE BRANCHED1 (Ramsay et al., 2011), one of the name giving members of the well-studied TEOSINTE BRANCHED1, CYYCLOIDEA, PROLIFERATING CELL NUCLEAR ANTIGEN BINDING FACTOR (TCP) gene family ( $\mathrm{Li}, 2015)$. TCP transcription factors are defined by the TCP domain, which is a 59 aa- long basic helix-loop-helix (bHLH) structure which provides the ability to bind GC-rich DNA sequence motifs (Martin-Trillo and Cubas, 2010). In barley, INT-C is encoded by $\mathrm{HORVU} 4 \mathrm{Hr}$ IG007040 and was identified as corresponding gene of the vrs 5 locus on chromosome 4 (Ramsay et al., 2011) being involved in the fertility of lateral spikelets.

To identify the genes closest to INT-C, the barley TCP gene family was analyzed using the latest barley annotation and genome sequence at http://webblast.ipkgatersleben.de/barley/viroblast.php and the TBLASTN algorithm with Arabidopsis TCP proteins or TCP domains as query sequence (Figure 1A; Supplemental Table S1). This family consists of 20 genes which contain a putative TCP-helix-loop-helix-type domain at the Nterminus (Figure 1B). The phylogenetic tree which was built based on multiple alignments of the TCP domain in TCP proteins showed that barley TCP proteins could be divided into two groups, as for all species so far (Figure 1A/B). The class I group was formed by nine predicted proteins related to the PCF rice factors (Kosugi and Ohashi, 1997), while class II was comprised of eleven predicted proteins related to the Antirrhinum CYC and CIN genes and to OsTB1 (Luo et al., 1996; Doebley et al., 1997; Nath et al., 2003; Takeda et al., 2003). In addition, the class II group could be further divided into two subclades: the CIN group formed by eight members and the CYC/TB1 group formed by three members. HvTC16 and HvTC17 from the class II CYC/TB1 contain an R domain that is also found in HvTC12 from the class II CIN group (Figure 1C), as previously described in Arabidopsis (Yao et al., 2007). 
272 Although in eudicots several CYC/TB1 sequences are found, and phylogenetic analyses have 273 suggested that duplications within this clade occurred at the base of eudicots, in monocots 274 only one type of CYC/TB1 has been identified (e.g., OsTB1) (Howarth and Donoghue, 2006).

275 Our phylogenetic analysis revealed that, based on the absence of the R domain, none of the 276 newly identified barley TCP genes can be considered as paralogue of INT-C.

277 As described for the model plant Arabidopsis, five of the CIN subclade members are post278 transcriptionally regulated by miRNA319 (AtTCP2, 3, 4, 10 and 24) (Palatnik et al., 2003; Ori 279 et al., 2007; Palatnik et al., 2007). In barley hvu-miR319a 280 (UUGGACUGAAGGGAGCUCCC) is encoded by CL16998_Contig1 (Ozhuner et al., 2013) 281 and expressed in roots, while it is not detectable in leaf tissue. The closest barley homologs of 282 these Arabidopsis genes are the five genes, HvTCP3, HvTCP6, HvTCP9, HvTCP12, and 283 HvTCP15. These barley CIN subclade members contain sequences with putative binding sites 284 for $h v u-m i R 319$ (Supplemental Table S1). Figure 1D shows the alignment of the target sites of 285 these genes with the miR319 sequence. This suggests that regulation of leaf development by a 286 redundant set of miRNA-regulated homologous TCP genes occurs in barley, while INT-C 287 does not represent a miR319 target. 
A
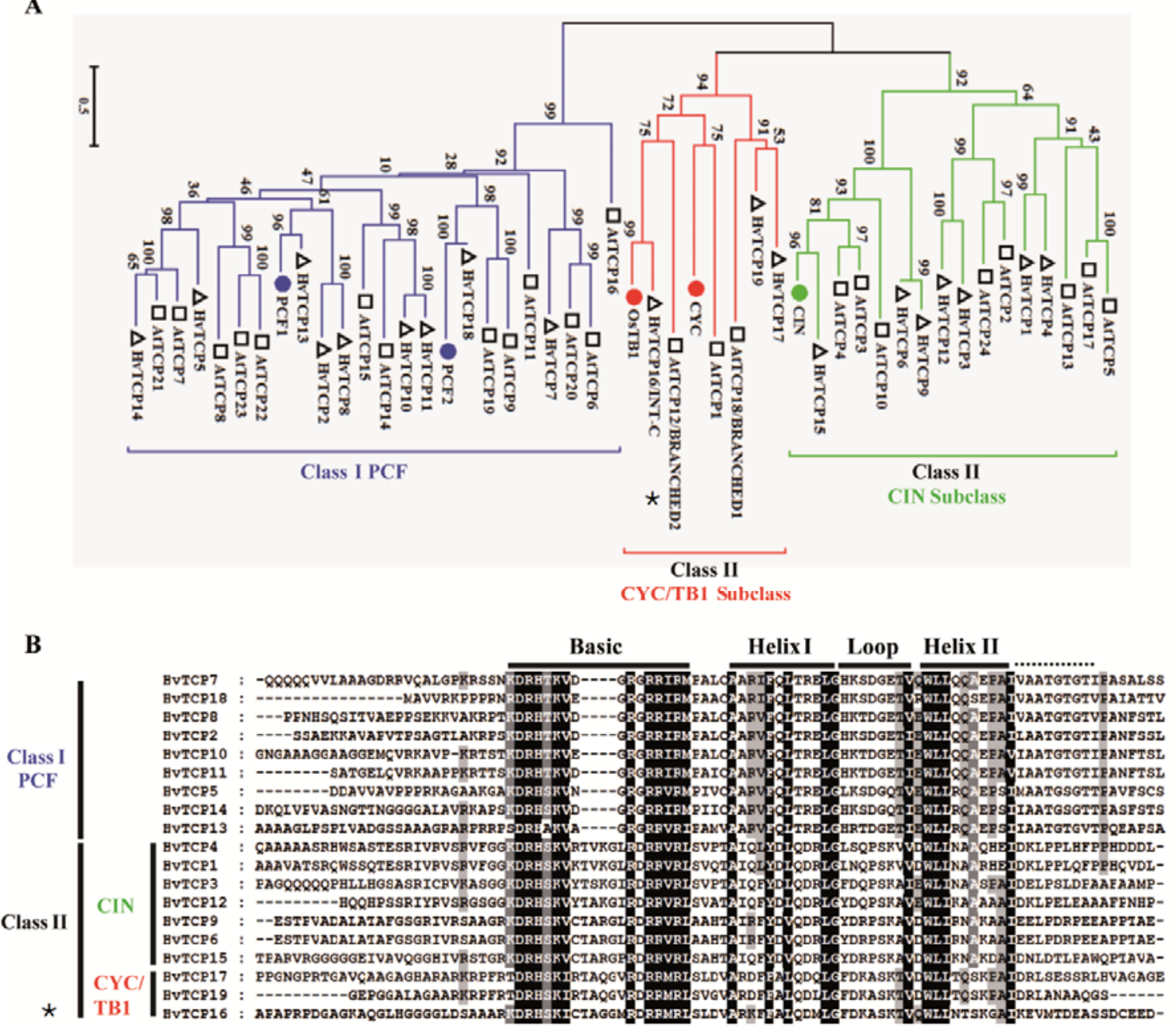

C

HVTCP16 : LITPDKESFTKARERAFERTREKNRMRWVTIIISTTINIEP- * HVTCP12 : SI SF SDSFVKARERAEDRSASVKDKEAGDDSAIRAPSA-

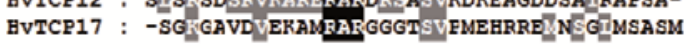

D HvTCP3 5' CAGGGGGC : CCCTTCAGTCCAATT 3' HVTCP12 5' CAGGGGGA: CCCTTCAGTCCAATT 3' HvTCP9 5' CGGGGAAA : CCCTTCAGTCCAGTG 3 ' HvTCP6 5' CGGGGAAA : CCCTTCAGTCCAGTG 3 ' HvTCP15 5' GAGGGGAC: CCCTTCAGTCCAGTA 3' HvTCP15 5' GAGGGGAC : CCCTTCAGTCCAGTA 3'
miR319a

Figure 1 Phylogenetic relations of Arabidopsis and barley TCP proteins. A) The phylogenetic tree of TCP proteins was built based on multiple alignment of the TCP domain amino acid sequence using the NeighborJoining method with 1000 bootstrap replicates. Blue, red and green lines indicate the PCF, CYC/TB1 and CIN clades, respectively. Each Arabidopsis protein is indicated by a square, each barley protein is indicated by a triangle. B) Alignment of the TCP domain and adjoining sequence for the predicted barley TCP proteins. Overall conserved amino acids are shaded in black. Amino acids $80 \%$ or $100 \%$ conserved in Class II or Class I are shaded in light gray and dark gray, respectively. The Basic, Helix I, Loop, and Helix II regions are indicated. C) Alignment of the R-domain of Class II subfamily members. Amino acids are expressed in the standard single letter code. Sequences were aligned with ClustalW and represented with Genedoc. D) Alignment of putative target areas for miR319 (aligned in reverse). INT-C (HvTCP16): asterisks

\section{INT-C loss-of-function leads to an early promotion of tiller bud outgrowth in barley}

Previous studies noticed that int-c mutants in various cultivars produce more tillers than the respective wild type plants during early vegetative stages (Ramsay et al., 2011; Liller et al., 2015). However, this increased tiller formation did not translate into more productive tillers. 
306

307

308

309

310

311

312

313

314

315

316

317

318

319

320

321

322

experiment described here performed with the near isogenic mutant BW421 (int-c.5) and the corresponding wild type confirmed these earlier observations. An increase in tiller number in int- $c$ was only detectable at the early developmental stages (Figure 2A) between two and five weeks after germination. At later developmental stages (6 to 8 weeks after germination), the pattern of tiller number was reversed. This observation correlated with an earlier anthesis of int-c compared to the wild type cv. Bowman (Supplementary Figure 1), leading to an earlier arrest of tiller bud production in int-c. The tillers of barley are formed in a sequential order, starting with the first tiller bud under the coleoptile. The development of the tiller buds in the axils of successive leaves was studied by dissecting the plants at different developmental stages (Figure 2B). To investigate the involvement of INT-C in bud initiation and bud outgrowth, the primary tiller buds were classified (Figure 2C/D) as dormant bud (800 1200 $\mu \mathrm{m})$, outgrowing bud $(1.5 \sim 100 \mathrm{~mm})$ or tiller emergence $(10 \sim 35 \mathrm{~cm})$ in each leaf axil at an early developmental stage ( 2 to 3 weeks after germination). Figure 2D indicates the enhanced bud outgrowth in int-c mutants compared to the wild type. This result suggests that the outgrowth of tiller buds is accelerated in int-c mutants at early developmental stages but is slowed down at later stages (> 5 weeks).

INT-C mRNA levels were analyzed by real-time qRT-PCR in different tissues and during spike development (Figure 2E/F). INT-C mRNA was detectable at highest levels in tiller buds, supporting its role in the control of tiller bud development. It was expressed at lower levels in other tissues such as root, stem and leaf. During spike meristem development mRNA levels of $I N T-C$ peaked at the glume primordium stage. In the later stages (stamen primordium and awn primordium) relative high levels of INT-C mRNA were persisting. This peak of expression correlated with the observation that after awn primordium stage profound differences in the development of lateral spikelet in int-c occurred compared to wild type (Ramsay et al., 2011). 
A

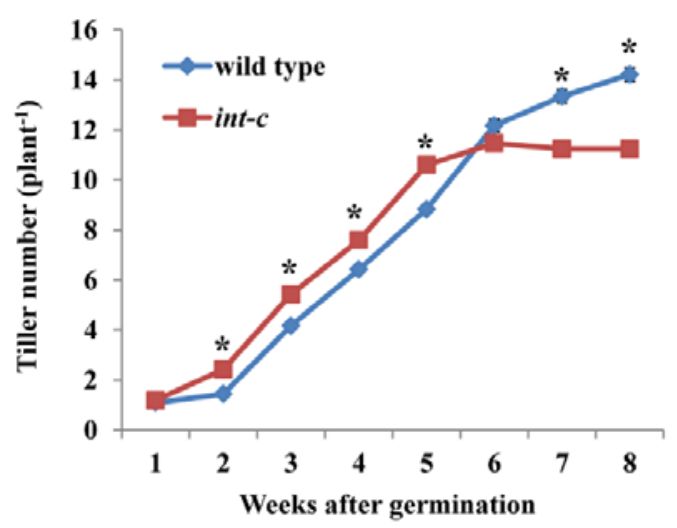

C

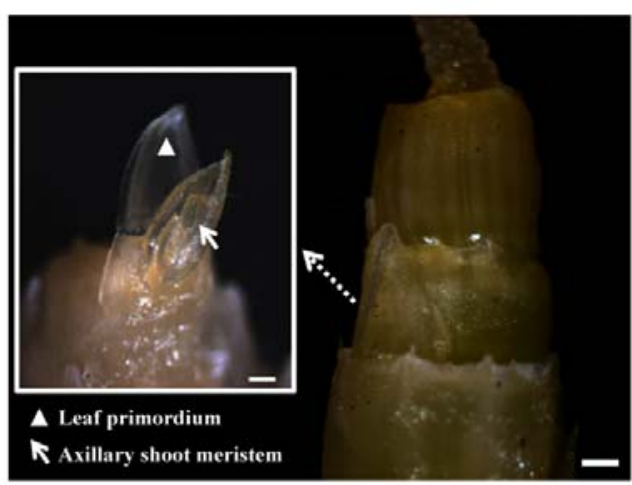

E lengths.
B

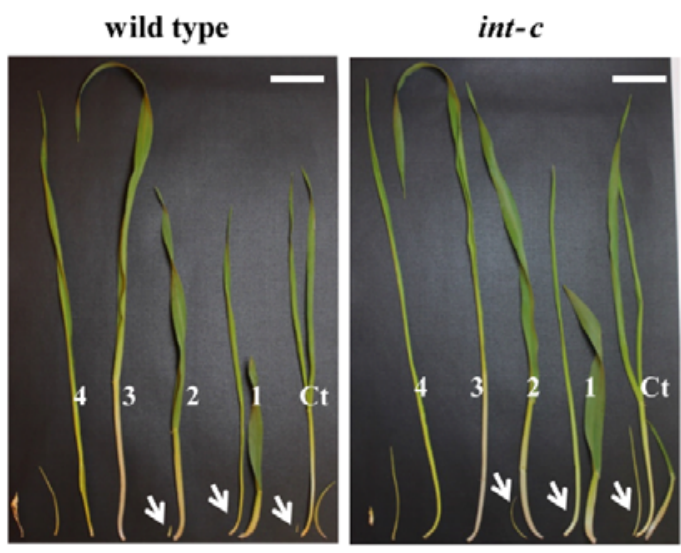

D

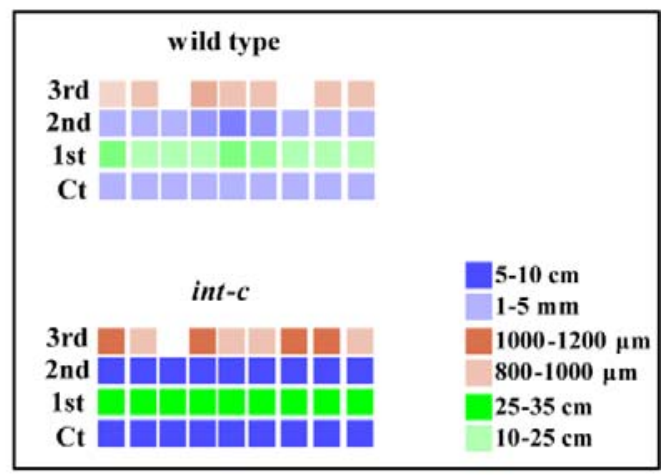

F

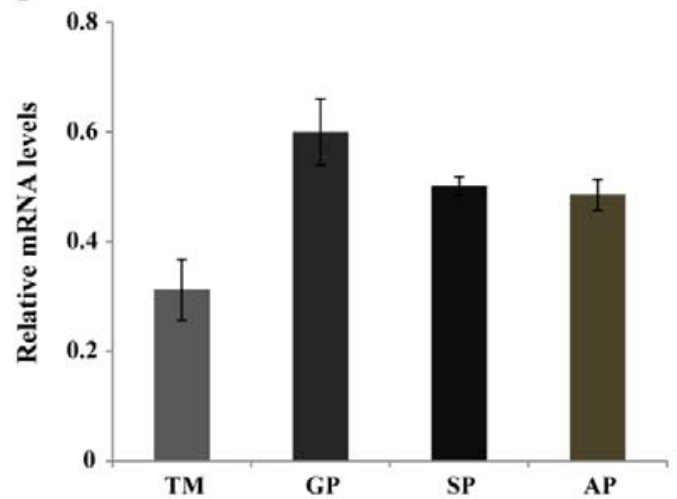

Figure 2. INT-C is involved in barley plant architecture by tiller bud outgrowth. Analysis of tiller development in wild type and int-c plants. A) Tiller number of int-c and wild type plants 1-8 weeks after germination ( $n=25-30$ plants). Asterisks indicate significant differences (Student's $t$ test, $\mathrm{P}<0.001$ ) between wild type and int-c mutant plants. B) Dissected tillers from successive leaf axils in about 2 to 3-week-old seedlings. $\mathrm{Ct}$, coleoptile tiller; $1-4$, order of leaves; bars $=5 \mathrm{~cm}$; arrows, tiller buds. C) Exemplary tiller bud formation stage in the third leaf axil. The area of the close-up view is outlined with a white box in the left image. Dissection of a tiller bud at this stage will reveal a shoot apex with leaf primordia and meristematic dome. Scale bars represent $200 \mu \mathrm{m}$. D) Schematic representations of tiller bud production in each leaf axil of the wild type and int-c in 2- to 3-week-old seedlings. Each column stands for a single plant, and each row stands for a leaf axil in order from bottom to top, starting with the coleoptile tiller. Different color squares denote different tiller bud

E) INT-C (HvTCP16) mRNA levels in different tissues and F) during spike development as analyzed by realtime qRT-PCR. Bars represent means $\pm \mathrm{SD} ; \mathrm{n}=3$ biological replicates. Serine/threonine protein phosphatase 
HvPP2A-4 mRNA was used as a reference. TM, triple mound; GP, glume primordium; SP, stamen primordium;

$\mathrm{AP}$, awn primordium.

\section{INT-C mRNA abundance decreased after decapitation}

Apical dominance is the inhibitory control exerted by the shoot apex over the outgrowth of the lateral buds (Cline, 1997). Decapitation stimulates bud reactivation after breaking the apical dominance (Hall and Hillman, 1975; Napoli et al., 1999; Cline, 2000; Tatematsu et al., 2005; Aguilar-Martinez et al., 2007). To analyze the involvement of INT-C in integrating the decapitation response into bud outgrowth we compared barley int-c mutant plants to the respective wild type plants. For this approach, three-week-old plants that had undergone early stem elongation, were decapitated. Two weeks later, two tiller buds of decapitated Bowman plants had elongated prematurely. Thus, total tiller number in decapitated wild-type plants reached the same level as in int-c mutants, in which decapitation had no effect (Figure 3A). To investigate whether this response was related with a transcriptional downregulation of $I N T-C$, mRNA levels in axillary buds were analyzed by real time qRT-PCR after decapitation, before any visible sign of bud outgrowth (Figure 3B). INT-C mRNA decreased significantly 6 dominance and required for bud activation.
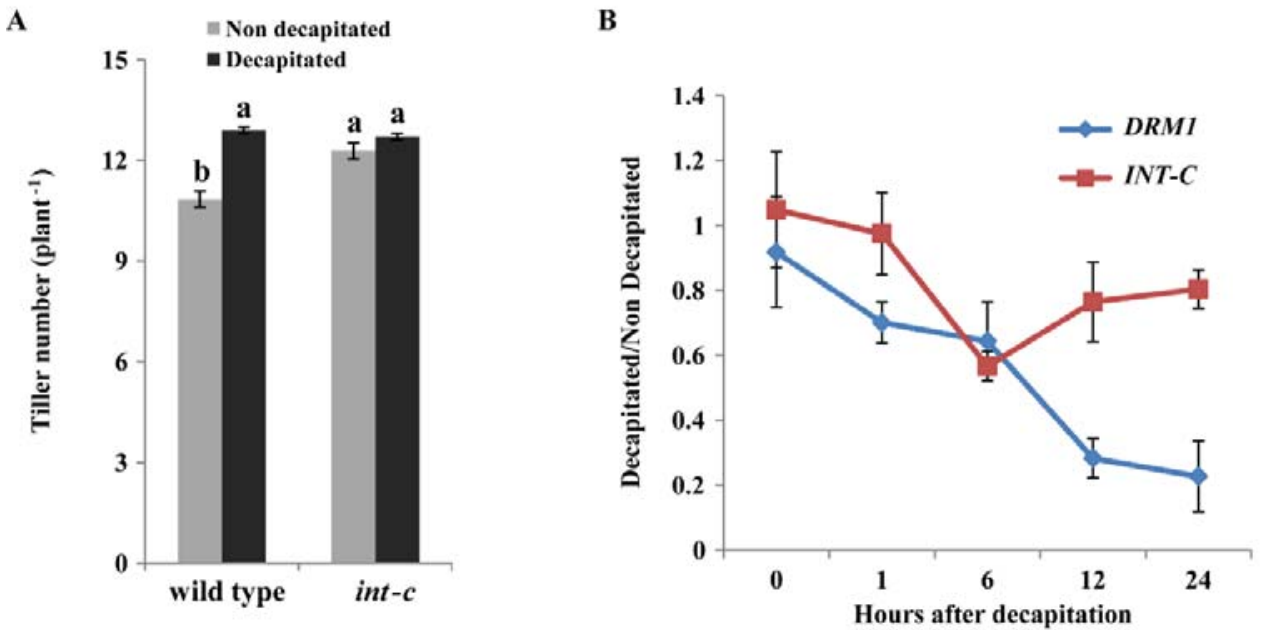

Figure 3. INT-C expression in response to decapitation. A) Tiller number of cv. Bowman (wild type) and int$c$ plants 2 weeks after decapitation. Bars represent means \pm SD; $n=3$ replicates with $\geq 16$ plants. Different letters indicate significant differences according to Tukey's test (P <0.05). B) Ratio of mRNA levels of INT-C and DRMI in tiller buds between decapitated and non-decapitated plants. Relative mRNA abundance of INT-C mRNA was analyzed by real-time q-RT-PCR. Bars represent means $\pm \mathrm{SD} ; n=4$ biological replicates. 
Serine/threonine protein phosphatase $H v P P 2 A-4$ was used as a reference gene. Analyzed is the early transcriptional response within 24 hours after decapitation.

\section{Transcriptome analysis of buds after decapitation}

To investigate the transcriptome response of dormant versus activated buds, Agilent $8 \times 60 \mathrm{~K}$ customized barley microarray expression analysis (Thirulogachandar et al., 2017) using total mRNA prepared from tiller buds at the early stem elongation stage was performed. The time point $24 \mathrm{~h}$ after decapitation was chosen for the following two reasons: 1) down-regulation of DRM1 expression was evident at this time point (Figure 3B) and 2) this time point was one day before the first visible effects of decapitation on the growth were detectable ( $2 \mathrm{~d}$ after decapitation, Figure 3A).

1704 differential expressed genes (DEGs) were detected in tiller buds of decapitated versus non-decapitated plants (Supplementary Table S2), among those 1011 were down-regulated and 693 up-regulated. Microarray results were confirmed by qRT-PCR for selected genes (Supplemental Figure 2). Besides DRM1, which was found among the down-regulated genes, several genes encoding transcription regulators were detected. 81 out of 494 DEGs regulated in opposite direction under shading conditions could be mapped to the term transcription regulator Associated with the term $\mathrm{ABA}$ are the auxin binding protein $\mathrm{ABP} 44$ and a putative ripening related bZIP Protein (CAB85632). The class of AP2-EREBP transcription regulators was found to be down regulated upon decapitation. The up-regulated genes included a large number of ribosomal proteins, cell organization, and cell cycle-related genes.

\section{Plant density affects INT-C expression}

Planting density affects shoot branching in many plant species. Low plant density results in more branches, compared to growth in dense plant stands as a result of a neighbor-sensing response (Casal et al., 1986). To test the impact of plant density on INT-C, wild type and int-c plants were grown in three different densities under greenhouse conditions (1, 5 and 10 plants per pot). Tiller numbers were counted until the early stem elongation stage (Figure 4). 
A

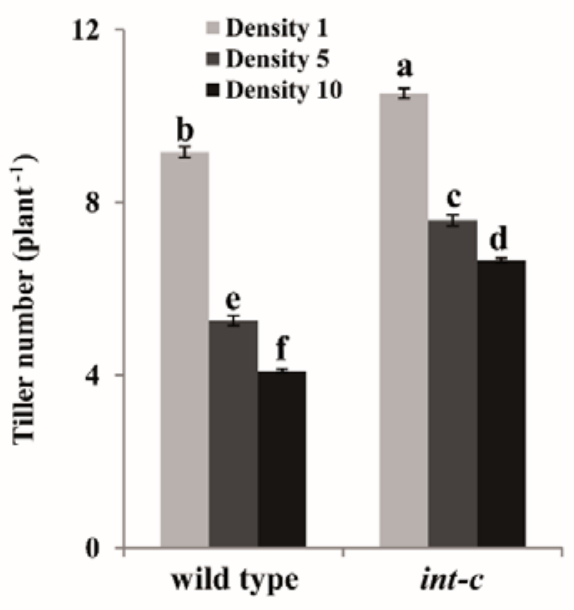

B

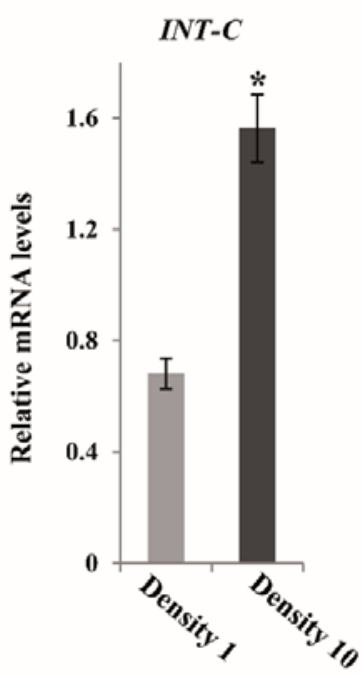

400

401

402

403

404

405

406

407

408

409

410

411

412

413

414

415

416

417

418

419

420

421

422

423

424

425

426

Figure 4. INT-C expression responds to planting density. A) Tiller number of wild type and int-c plants grown at planting densities of 1,5 , or 10 plants per pot. Plants were analyzed 5 weeks after sowing. Bars represent means $\pm \mathrm{SD} ; n=3$ replicates with $\geq 20$ plants. Different letters indicate significant differences according to Tukey's test $(\mathrm{P}<0.01)$. B) Transcript levels of INT-C in the tiller bud tissue analyzed by real-time PCR at a density of 1 or 10 plants per pot. Bars represent means $\pm \mathrm{SD} ; n=3$ biological replicates. Serine/threonine protein phosphatase $H v P P 2 A-4$ was used as a reference gene. Asterisk indicates significant difference according to Student's $t$ test at $* \mathrm{P}<0.001$.

Wild-type plants responded to increased planting density with reduced tillering. At a density of ten plants per pot, tiller bud suppression was more than half, as tiller number was $56 \%$ lower than in plants grown at one plant per pot. However, int-c mutants showed reduced sensitivity to this condition (33\% reduction compared with plants at one plant per pot). The mRNA levels of INT-C were then analyzed by RT-qPCR in wild type plants grown at low (one plant per pot) and high (ten plants per pot) density. At high density, INT-C mRNA levels showed a two-fold increase compared to those at low density (Figure 4B). These results support the involvement of transcriptional regulation of INT-C on bud dormancy.

\section{INT-C is upregulated as part of the shade avoidance response}

To further examine whether INT-C is participating in the shade avoidance response, plants were grown under two different light conditions: control light (PAR: $840 \mu \mathrm{mol} \mathrm{m}^{-2} \mathrm{~s}^{-1}$; R:FR ratio $=2.2$ ), and low R:FR light mimicking shade imposition by neighboring plants (green shade, PAR: $260 \mu \mathrm{mol} \mathrm{m} \mathrm{s}^{-2}$; R:FR ratio $=0.2$ ) (Kegge et al., 2013). To minimize a putative bias resulting from variations in leaf number and int-c mediated earlier flowering, plants were grown at conditions attenuating the int-c early flowering phenotype (Figure 5A).

The shading treatment was started at the two-leaf stage. Four weeks later primary tiller number was quantified. Bowman plants grown under shade conditions responded strongly and 
427 had 4 times less tillers than plants grown in control conditions (Figure 5B), indicating that

428 exposure of plants with young vegetative buds to a low R:FR ratio promotes bud arrest in 429 barley. In contrast, the response of int-c mutants to shading was much weaker. int-c plants 430 grown under shade had only 1.4 times fewer tillers than plants grown under normal light 431 conditions (Figure 5A/B). Other phenotypic shade avoidance responses, such as hyponasty 432 and stem elongation, were indistinguishable between the wild type and mutant plants (Figure $4335 \mathrm{~A}$ ). The short-term response of INT-C to shade treatment was analyzed by transferring plants 434 at the five-leaf stage (when plants had small vegetative buds) to low R:FR light. The mRNA 435 levels of INT-C in tiller buds increased after 4,6 or $8 \mathrm{~h}$ exposure to shade, indicating a 436 transcriptional activation of INT-C in response to shade (Figure 5C). This result is in 437 agreement with the increase of tillers in plants grown in dense stands. The higher tiller 438 number in int-c coincided with a lower concentration of ABA in tiller buds (Figure 5B, D), 439 supporting the role of ABA as mediator of INT-C-dependent tiller bud suppression in the 440 shade. 

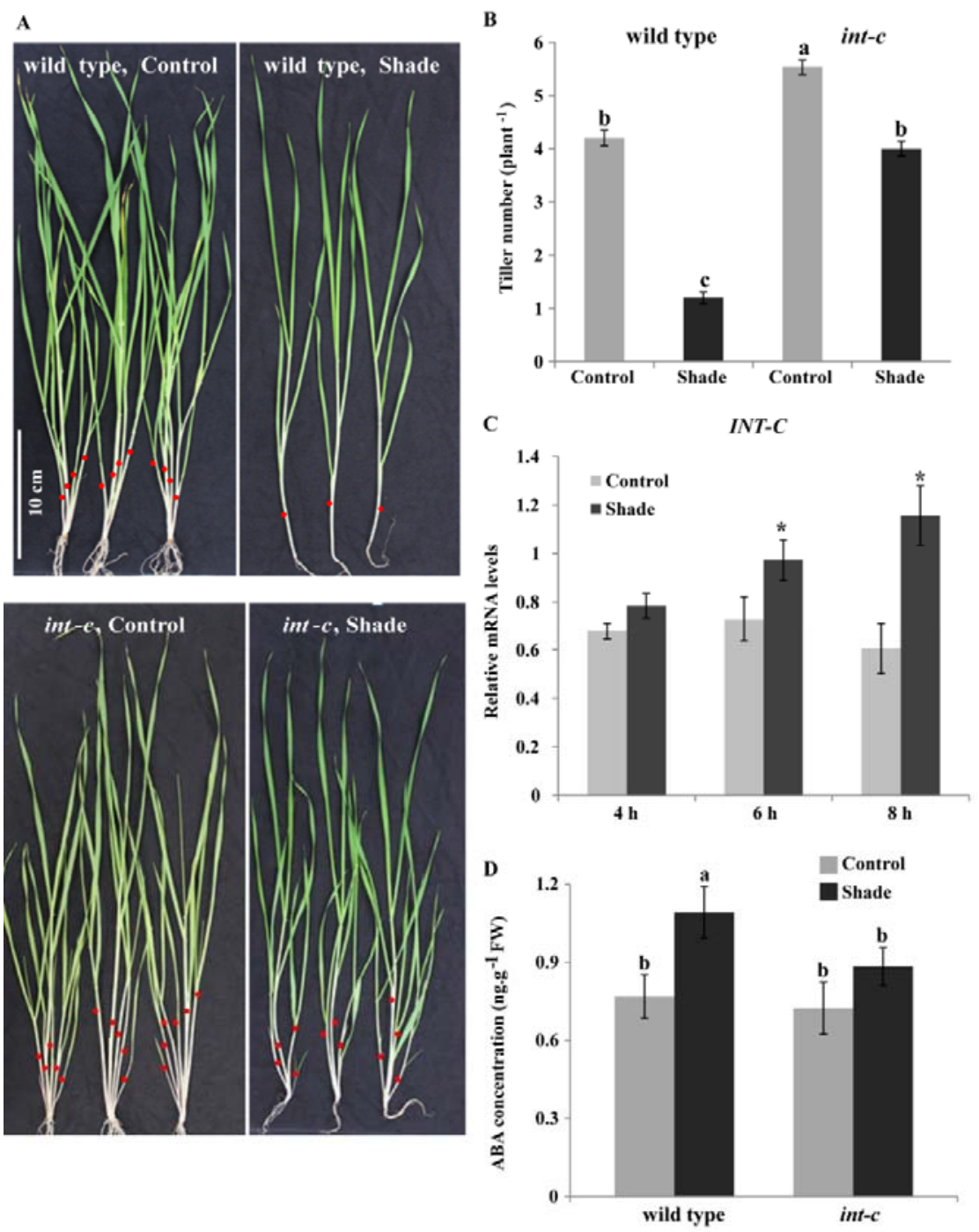

\section{Transcriptome analysis of tiller buds after shading identifies INT-C dependent genes}

454 To get further insight into the molecular mechanisms of INT-C-mediated growth responses, 455 the transcriptome of tiller buds in wild type and int-c plants was analyzed. The plants were exposed to control conditions or shade (Figure 5) and the transcriptome was analyzed $6 \mathrm{~h}$ after exposure to shade using an Agilent $8 \times 60 \mathrm{~K}$ customized barley microarray. As INT-C 
458 expression was highest in buds (Figure 1), we selected this tissue for detailed analysis of RNA 459 extraction.

460 While under control conditions a minor influence of int-c-dependent transcript changes was 461 found, 305 differentially expressed genes (DEGs) were identified between WT vs int-c, out of 462 which 185 were up- and 120 down-regulated. Under shading a stronger effect of int-c on the 463 transcriptome was noted. In wild type buds, 2726 shade-responsive DEGs (1803 DEG up- and 464923 DEGs down-regulated) were detected. In the int-c mutant, a total of 906 DEGs were 465 identified in response to shade with 226 up-regulated genes and 680 down-regulated genes 466 (Figure 6, Supplemental Table S2). DEGs detected by microarray were validated and 467 confirmed for five upregulated and five downregulated genes by qRT-PCR (Supplementary 468 Figure 3). The number of DEGs in response to shading decreased by $\sim 67 \%$ in int-c (Figure 6 , 469 Supplementary Table S2). This drop supports the hypothesis of the involvement of INT-C in 470 the shade response. The overlapping DEGs, detectable in wild type and int-c are related to a common shade avoidance response independent of INT-C, while DEGs detectable in the wild type could directly or indirectly depend on INT-C function. These 2154 DEGs were termed INT-C-dependent genes of the shade response (Figure 6, Supplementary Table S2).

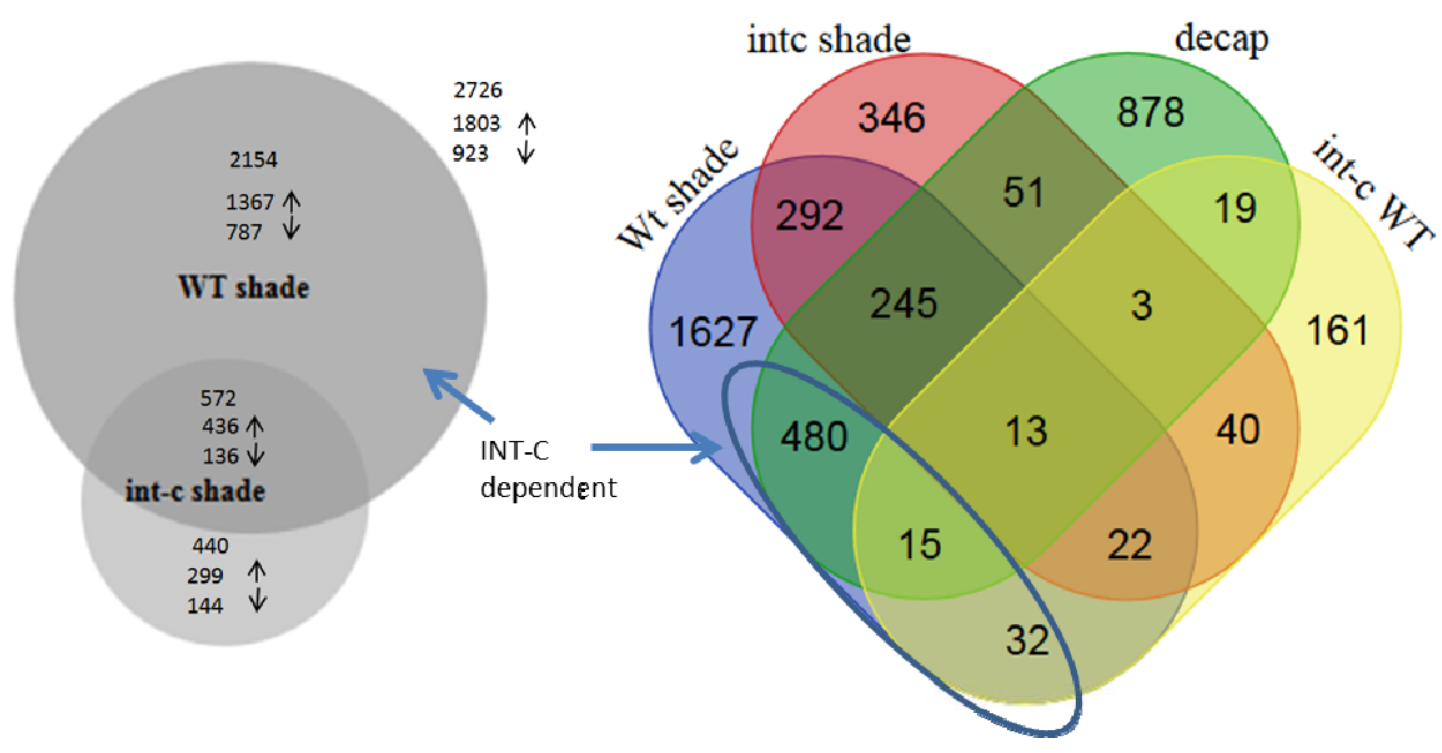

Figure 6. Venn diagram of differentially expressed genes (DEGs) detected after shade treatment in cv. Bowman wild type (Wt shade) and int-c (int-c shade). These blocks were compared to DEGs detectable after decapitation 
2 at an FDR of $\mathrm{p}<0.05$. (shade: INT-C mRNA induced, int-c: no functional INT-C, decap: INT-C mRNA reduced).

In Bowman buds, the upregulation of INT-C after shading (2.56-fold increase at an FDR of 4.78E-04 could be confirmed. In the BW421 (int-c.5) deletion mutant a similar induction of INT-C (2.10-fold increase, FDR = 0.0086) was detectable (Supplementary Table S2). However, in the int-c.5 mutant the deletion in the INT-C gene leads to a frameshift in the Cterminus downstream of the R-domain. This mutation leads to a nonfunctional gene product.

The inspection of the respective marker genes HAT4/ATHB2, PIF3 and PIF4 (Leivar and Monte, 2014) by their transcriptional activation validated the applied experimental shade conditions (Supplementary Table S2). Among the significantly upregulated genes after shade in the wild type, transcript levels of the marker gene DRMI that is associated with tiller bud dormancy (Stafstrom et al., 1998; Tatematsu et al., 2005) were found to be more than twofold higher (Supplementary Table S2).

As shown in Figure 5A the shade response led to a transcriptional activation of INT-C and a repression of tiller outgrowth. In contrast, the decapitation of barley plants resulted in a reduced expression of INT-C and the opposite phenotype. As INT-C expression was reduced under this simulated condition, the generated dataset was used to validate the list of INT-Cdependent shade response genes (Supplementary Table S2).

The Venn diagram (Figure 6) illustrates 753 overlapping DEGs after decapitation and after shading (27\% of 2726 DEGs after shading and 44\% of 1704 DEGs after decapitation). 495 (29\%) of the decapitation-induced DEGs were also detectable in response to shading. Almost all of these DEGs were oppositely regulated after decapitation and shading, respectively (Supplementary table S3). This list was defined as INT-C dependent genes.

MapMan software was used to define gene functional categories (Thimm et al., 2004; Usadel et al., 2005). For the INT-C dependent genes we identified hormone- and stress-related genes among the upregulated genes and cell division- and protein synthesis-related genes among the downregulated genes as the most prominent functional categories.

As all INT-C-dependent genes showed opposite responses after decapitation and under shade, these gene sets infer the causal mechanisms associated with bud activation and bud arrest, respectively. 123 genes $(25 \%)$ found to be upregulated after decapitation were downregulated under shade while $372(75 \%)$ genes downregulated after decapitation were upregulated under shade (Figure 6; Supplementary Table S3). During decapitation-induced bud activation, INT-C was rapidly downregulated (Figure 3B). Further, a strong overlap of DEGs responding to decapitation and shading was observed. Theoretically, the 372 
515 downregulated (after decapitation) genes might be directly involved in the promotion of

516 axillary bud arrest. This group included a number of genes related to ethylene, abscisic acid, 517 auxin, and gibberellin signaling (AP2/ERBP, ACC, ERF1, IAA17, and GID1L2), as well as 518 protein degradation (SKIP1, SKIP5, SKP2A, UBQ3 and UBQ4). Moreover, genes related to 519 sugar metabolism and transport also identified within that group (TPS6, sucrose transporter). 520 Trehalose-6-phosphate is known to be involved in sugar signaling (Figueroa and Lunn, 2016).

521 On the other hand, the 123 upregulated genes (after decapitation) could be involved in 522 promoting axillary bud growth. This group included many genes associated with chloroplast 523 function and chlorophyll synthesis (chlorophyll binding protein, ATP synthase), protein 524 synthesis (EF-Ts, ribosomal protein), and chromatin structure (HISTONE H3.2, HISTONE 525 2B. 3). This set of genes was co-regulated with a subset of genes related to functional categories involved in thylakoid and photosynthesis (Supplementary Figure 4).

\section{Discussion}

The present study shows that $I N T-C$ is transcriptionally regulated by apical dominance and by light perception and that INT-C expression in tiller buds regulates tillering in response to these signals. This highlights the role of $I N T-C$ as a major transcriptional regulator integrating endogenous with environmental signals to determine the outgrowth of tiller buds. Based on the microarray hybridization experiment INT-C dependent genes are defined.

\section{INT-C integrates environmental signals to regulate tiller bud outgrowth}

537 In crop plants, tillering is an important agronomic trait for yield formation. However, in barley little is known about the genetic mechanisms acting inside tiller buds to cause growth arrest. Here, we show that the bHLH transcription factor INTERMEDIUM-C (INT-C) is involved in the integration of different branching signals mediating a suppressive effect on bud outgrowth (Figure 3). INT-C itself is regulated on the transcriptional level as response of the investigated environmental conditions. This modulation of INT-C transcription appears to be under tight regulation of environmental and developmental stimuli that are correlated with bud outgrowth and activation of tillering. INT-C upregulation was observed after shading or under high planting densities (Figure 3,4), linked to reduced tiller numbers; on the contrary suppression of INT-C expression, i.e., after decapitation, triggered bud outgrowth (Figure 5).

547 This emphasizes a role of INT-C as a regulator integrating signals within the axillary bud to 548 determine tiller number. This finding agrees with the results in rice where TB1 was also 
549 reported to mediate a negative function in tillering (Takeda et al., 2003; Choi et al., 2012). A

550 comparable approach using transgenic overexpression and antisense mediated repression of

551 INT-C resulted in the modulation of tiller and panicle development in rice. The influence and 552 integration of environmental stimuli in rice was only addressed in response to greenhouse and 553 paddy field conditions. In maize the involvement of the SPL gene family as direct regulators 554 of TB1 on plant architectural traits was described and optimized plants were engineered for 555 high-density planting (Wei et al., 2018).

556

557 Definition of $I N T$ - $C$-dependent genes

558

559

560

561

562

563

564

565

566

567

568

569

570

571
The analysis of the shading response at the transcriptome level led to the identification of important differentially expressed genes that were directly or indirectly dependent on INT-C. Our data suggest that the number of INT-C-dependent genes (229 up- and 82 downregulated) was closely associated with tiller bud activation, confirmed through int-c mutant study, and INT-C function inferred from the stimulus experiments (either shade or decapitation). These target genes are promising candidates to play an important role in tiller bud transition between repression and promotion of growth. The MAPMAN-based categorization of DEGs resulted in a significant overrepresentation of the term thylakoid and genes associated with photosynthesis. In addition to this, several target genes of sink/source properties of a tissue are found (e.g. TPS6, sucrose transporters). This supports the idea of bud activation, accompanied by generation of a new initial sink tissue. Also, photosynthesis will be activated in this new formed tiller. The scheme in Figure 7 show the integration of the respective categories and important genes involved in INT-C mediated bud activation. 


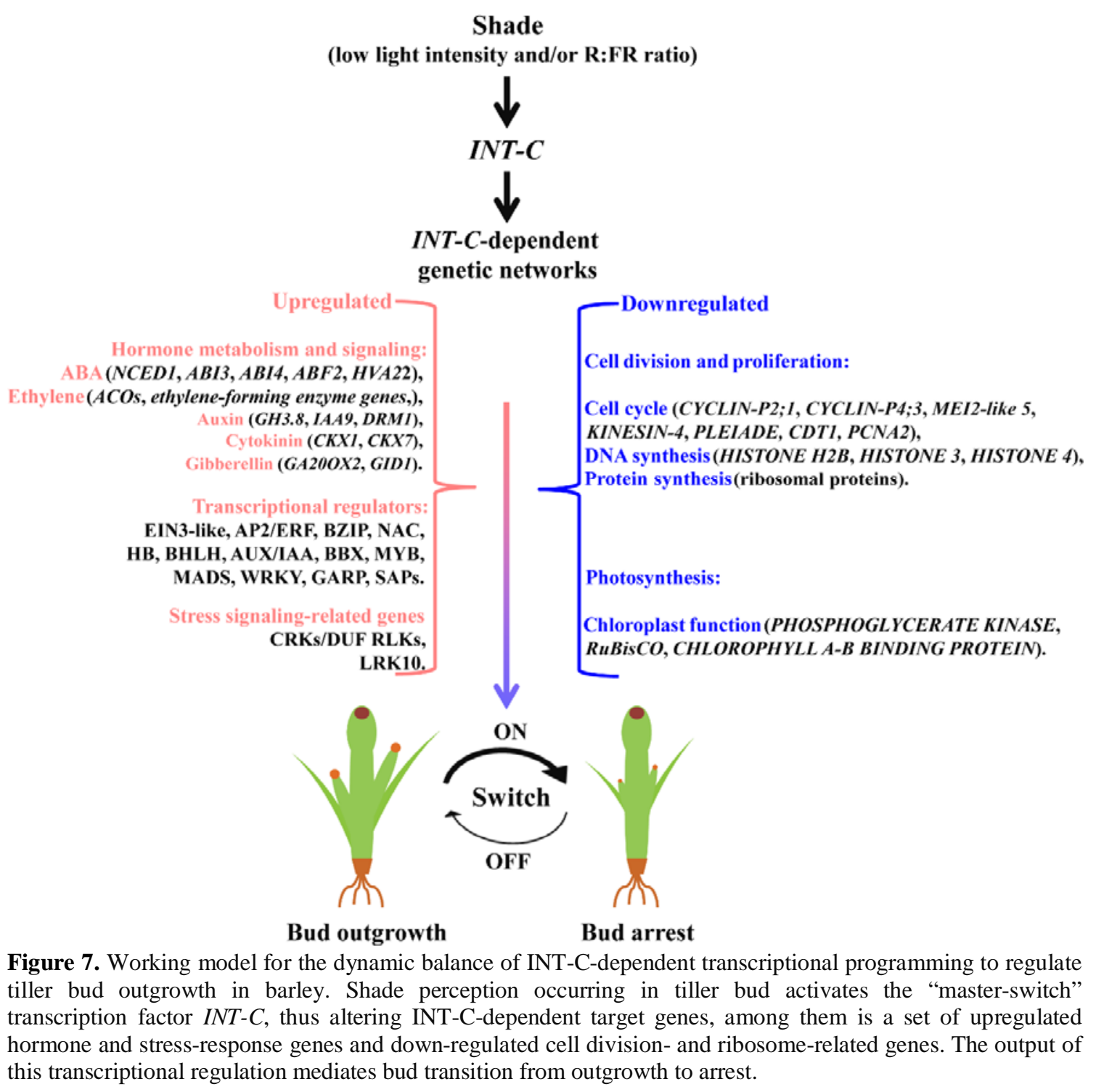

\section{ABA signaling and the promotion of bud dormancy}

$\mathrm{ABA}$ has been related to the maintenance and promotion of bud dormancy in many plant species: elevated ABA levels in buds are associated with the inhibition of branching during plant development (Tamas et al., 1979; Knox and Wareing, 1984; Gocal et al., 1991; Mader et al., 2003; Destefano-Beltran et al., 2006; Ruttink et al., 2007; Eggert and von Wiren, 2017), as well as in the context of responses to low R:FR ratios (Tucker and Mansfield, 1971; Reddy et al., 2013; Gonzalez-Grandio et al., 2017). Moreover, a correlation has been found between the upregulation of ABA-response genes in axillary buds and bud dormancy (Ruttink et al., 2007; Gonzalez-Grandio et al., 2013; Kebrom and Mullet, 2016). So far, neither ABA measurements have been reported in tiller buds, nor ABA-inducible genes have been studied in the tiller bud development of barley (Hussien et al., 2014). Nonetheless, it has been 
590 supposed that in barley a correlation exists between ABA signaling and bud arrest 591 (Finkelstein, 2013). Recently, (Luo et al., 2019) and colleagues have shown that application

592

593

594

595

596

597

598

599

600

601

602

603

604

605

606

607

608

609

610

611

612

613

614

615

616

617

618

619

620

621

622

623

624

625

626

627

628 of $\mathrm{ABA}$ to hydroponic cultures of rice strigolactone mutants and wild-type plants suppressed axillary bud outgrowth. Strigolactone and ABA biosynthesis share the same precursor and are closely related in regulating the tiller number in barley (Wang et al., 2018). In the present study we demonstrate that INT-C as regulatory hub regulates various ABA hormone pathway genes as well decapitation and shade responses. The large number of transcription factors found in the list of defined INT-C-dependent genes also points toward a function of INT-C as regulatory hub controlling a complex downstream network. Our transcript data provide evidence that wild-type tiller buds display a strong increase in the global response of ABArelated genes, while int-c buds, which exhibit less dormancy and continue to grow, show reduced ABA-related responses. Consistently, the number of ABA-related genes in the tiller buds was higher after shading. These findings are subsumed in the model (Figure 7) building the hypothesis that INT-C employs the ABA signaling pathway in conjunction with other hormones to mediate bud growth arrest.

Author contributions: H.W. planned and designed the research. H.W. performed experiments and H.W., C.S. and M.K. analyzed the data. H.W., M.K., N. S, and N.v.W. conceived the study. H.W. and M.K wrote the manuscript.

Funding information: This work was supported by IZN (Interdisciplinary Centre for Crop Plant Research), Halle (Saale), Saxony-Anhalt, Germany and the Leibniz Graduate School "Yield Formation in cereals-overcoming yield-limiting factors" IPK. We thank Barbara Kettig, IPK Gatersleben, for excellent technical assistance.

\section{References}

Aguilar-Martinez JA, Poza-Carrion C, Cubas P (2007) Arabidopsis BRANCHED1 acts as an integrator of branching signals within axillary buds. Plant Cell 19: 458-472

Ballare CL (1999) Keeping up with the neighbours: phytochrome sensing and other signalling mechanisms (vol 4, pg 97, 1999). Trends in Plant Science 4: 201-201

Braun N, de Saint Germain A, Pillot JP, Boutet-Mercey S, Dalmais M, Antoniadi I, Li X, MaiaGrondard A, Le Signor C, Bouteiller N, Luo D, Bendahmane A, Turnbull C, Rameau C (2012) The Pea TCP Transcription Factor PsBRC1 Acts Downstream of Strigolactones to Control Shoot Branching. Plant Physiology 158: 225-238

Casal JJ, Sanchez RA, Deregibus VA (1986) The Effect of Plant-Density on Tillering - the Involvement of R/Fr Ratio and the Proportion of Radiation Intercepted Per Plant. Environmental and Experimental Botany 26: 365-371

Chen M, Chory J, Fankhauser C (2004) Light signal transduction in higher plants. Annual Review of Genetics 38: 87-117 
Choi MS, Woo MO, Koh EB, Lee J, Ham TH, Seo HS, Koh HJ (2012) Teosinte Branched 1 modulates tillering in rice plants. Plant Cell Rep 31: 57-65

Cline MG (1997) Concepts and terminology of apical dominance. American Journal of Botany 84: 1064-1069

Cline MG (2000) Execution of the auxin replacement apical dominance experiment in temperate woody species. American Journal of Botany 87: 182-190

Destefano-Beltran L, Knauber D, Huckle L, Suttle J (2006) Chemically forced dormancy termination mimics natural dormancy progression in potato tuber meristems by reducing $A B A$ content and modifying expression of genes involved in regulating $A B A$ synthesis and metabolism. Journal of Experimental Botany 57: 2879-2886

Devlin PF, Yanovsky MJ, Kay SA (2003) A genomic analysis of the shade avoidance response in Arabidopsis. Plant Physiology 133: 1617-1629

Doebley J, Stec A, Hubbard L (1997) The evolution of apical dominance in maize. Nature 386: 485488

Duek PD, Fankhauser C (2005) bHLH class transcription factors take centre stage in phytochrome signalling. Trends in Plant Science 10: 51-54

Eggert K, von Wiren N (2017) Response of the plant hormone network to boron deficiency. New Phytol 216: 868-881

Franklin KA, Quail PH (2010) Phytochrome functions in Arabidopsis development. Journal of Experimental Botany 61: 11-24

Gocal GFW, Pharis RP, Yeung EC, Pearce D (1991) Changes after Decapitation in Concentrations of Indole-3-Acetic-Acid and Abscisic-Acid in the Larger Axillary Bud of Phaseolus-Vulgaris L-CV Tender Green. Plant Physiology 95: 344-350

Gonzalez-Grandio E, Pajoro A, Franco-Zorrilla JM, Tarancon C, Immink RGH, Cubas P (2017) Abscisic acid signaling is controlled by a BRANCHED1/HD-ZIP I cascade in Arabidopsis axillary buds. Proceedings of the National Academy of Sciences of the United States of America 114: E245E254

Gonzalez-Grandio E, Poza-Carrion C, Sorzano CO, Cubas P (2013) BRANCHED1 promotes axillary bud dormancy in response to shade in Arabidopsis. Plant Cell 25: 834-850

Hall SM, Hillman JR (1975) Correlative Inhibition of Lateral Bud Growth in Phaseolus-Vulgaris L Timing of Bud Growth Following Decapitation. Planta 123: 137-143

Hornitschek P, Kohnen MV, Lorrain S, Rougemont J, Ljung K, Lopez-Vidriero I, Franco-Zorrilla JM, Solano R, Trevisan M, Pradervand S, Xenarios I, Fankhauser C (2012) Phytochrome interacting factors 4 and 5 control seedling growth in changing light conditions by directly controlling auxin signaling. Plant Journal 71: 699-711

Howarth DG, Donoghue MJ (2006) Phylogenetic analysis of the "'ECE" (CYC/TB1) clade reveals duplications predating the core eudicots. Proceedings of the National Academy of Sciences of the United States of America 103: 9101-9106

Hussien A, Tavakol E, Horner DS, Munoz-Amatriain M, Muehlbauer GJ, Rossini L (2014) Genetics of Tillering in Rice and Barley. Plant Genome 7

Kang YH, Khan S, Ma XY (2009) Climate change impacts on crop yield, crop water productivity and food security - A review. Progress in Natural Science-Materials International 19: 1665-1674

Kebrom TH, Brutnell TP, Finlayson SA (2010) Suppression of sorghum axillary bud outgrowth by shade, phyB and defoliation signalling pathways. Plant Cell and Environment 33: 48-58

Kebrom TH, Burson BL, Finlayson SA (2006) Phytochrome B represses Teosinte Branched1 expression and induces sorghum axillary bud outgrowth in response to light signals. Plant Physiology 140: 1109-1117

Kebrom TH, Mullet JE (2016) Transcriptome Profiling of Tiller Buds Provides New Insights into PhyB Regulation of Tillering and Indeterminate Growth in Sorghum. Plant Physiology 170: 22322250

Kebrom TH, Spielmeyer W, Finnegan EJ (2013) Grasses provide new insights into regulation of shoot branching. Trends in Plant Science 18: 41-48 
Kegge W, Weldegergis BT, Soler R, Vergeer-Van Eijk M, Dicke M, Voesenek LACJ, Pierik R (2013) Canopy light cues affect emission of constitutive and methyl jasmonate-induced volatile organic compounds in Arabidopsis thaliana. New Phytologist 200: 861-874

Knox JP, Wareing PF (1984) Apical Dominance in Phaseolus-Vulgaris L - the Possible Roles of Abscisic and Indole-3-Acetic-Acid. Journal of Experimental Botany 35: 239-244

Kong LS, Abrams SR, Owen SJ, Graham H, von Aderkasi P (2008) Phytohormones and their metabolites during long shoot development in Douglas-fir following cone induction by gibberellin injection. Tree Physiology 28: 1357-1364

Koppolu R, Anwar N, Sakuma S, Tagiri A, Lundqvist U, Pourkheirandish M, Rutten T, Seiler C, Himmelbach A, Ariyadasa R, Youssef HM, Stein N, Sreenivasulu N, Komatsuda T, Schnurbusch T (2013) Six-rowed spike4 (Vrs4) controls spikelet determinacy and row-type in barley. Proc Natl Acad Sci U S A 110: 13198-13203

Kosugi S, Ohashi Y (1997) PCF1 and PCF2 specifically bind to cis elements in the rice proliferating cell nuclear antigen gene. Plant Cell 9: 1607-1619

Leivar P, Monte E (2014) PIFs: Systems Integrators in Plant Development. Plant Cell 26: 56-78

Li S (2015) The Arabidopsis thaliana TCP transcription factors: A broadening horizon beyond development. Plant Signal Behav 10: e1044192

Liller CB, Neuhaus R, von Korff M, Koornneef M, van Esse W (2015) Mutations in Barley Row Type Genes Have Pleiotropic Effects on Shoot Branching. Plos One 10

Livak KJ, Schmittgen TD (2001) Analysis of relative gene expression data using real-time quantitative PCR and the 2(T)(-Delta Delta C) method. Methods 25: 402-408

Luo D, Carpenter R, Vincent C, Copsey L, Coen E (1996) Origin of floral asymmetry in Antirrhinum. Nature 383: 794-799

Luo L, Takahashi M, Kameoka H, Qin R, Shiga T, Kanno Y, Seo M, Ito M, Xu G, Kyozuka J (2019) Developmental analysis of the early steps in strigolactone-mediated axillary bud dormancy in rice. Plant J 97: 1006-1021

Mader JC, Emery RJN, Turnbull CGN (2003) Spatial and temporal changes in multiple hormone groups during lateral bud release shortly following apex decapitation of chickpea (Cicer arietinum) seedlings. Physiologia Plantarum 119: 295-308

Martin-Trillo M, Cubas P (2010) TCP genes: a family snapshot ten years later. Trends Plant Sci 15: 3139

Martin-Trillo M, Grandio EG, Serra F, Marcel F, Rodriguez-Buey ML, Schmitz G, Theres K, Bendahmane A, Dopazo H, Cubas P (2011) Role of tomato BRANCHED1-like genes in the control of shoot branching. Plant Journal 67: 701-714

Minakuchi K, Kameoka H, Yasuno N, Umehara M, Luo L, Kobayashi K, Hanada A, Ueno K, Asami T, Yamaguchi S, Kyozuka J (2010) FINE CULM1 (FC1) Works Downstream of Strigolactones to Inhibit the Outgrowth of Axillary Buds in Rice. Plant and Cell Physiology 51: 1127-1135

Napoli CA, Beveridge CA, Snowden KC (1999) Reevaluating concepts of apical dominance and the control of axillary bud outgrowth. Current Topics in Developmental Biology, Vol 44 44: 127169

Nath U, Crawford BCW, Carpenter R, Coen E (2003) Genetic control of surface curvature. Science 299: $1404-1407$

Ori N, Cohen AR, Etzioni A, Brand A, Yanai O, Shleizer S, Menda N, Amsellem Z, Efroni I, Pekker I, Alvarez JP, Blum E, Zamir D, Eshed Y (2007) Regulation of LANCEOLATE by miR319 is required for compound-leaf development in tomato. Nature Genetics 39: 787-791

Ozhuner E, Eldem V, Ipek A, Okay S, Sakcali S, Zhang B, Boke H, Unver T (2013) Boron stress responsive microRNAs and their targets in barley. PLoS One 8: e59543

Palatnik JF, Allen E, Wu XL, Schommer C, Schwab R, Carrington JC, WeigeI D (2003) Control of leaf morphogenesis by microRNAs. Nature 425: 257-263

Palatnik JF, Wollmann H, Schommer C, Schwab R, Boisbouvier J, Rodriguez R, Warthmann N, Allen E, Dezulian T, Huson D, Carrington JC, Weigel D (2007) Sequence and expression differences underlie functional specialization of Arabidopsis MicroRNAs miR159 and miR319.

Developmental Cell 13: 115-125 
Quevillon E, Silventoinen V, Pillai S, Harte N, Mulder N, Apweiler R, Lopez R (2005) InterProScan: protein domains identifier. Nucleic Acids Research 33: W116-W120

Ramsay L, Comadran J, Druka A, Marshall DF, Thomas WT, Macaulay M, MacKenzie K, Simpson C, Fuller J, Bonar N, Hayes PM, Lundqvist U, Franckowiak JD, Close TJ, Muehlbauer GJ, Waugh $\mathbf{R}$ (2011) INTERMEDIUM-C, a modifier of lateral spikelet fertility in barley, is an ortholog of the maize domestication gene TEOSINTE BRANCHED 1. Nat Genet 43: 169-172

Reddy SK, Holalu SV, Casal JJ, Finlayson SA (2013) Abscisic Acid Regulates Axillary Bud Outgrowth Responses to the Ratio of Red to Far-Red Light. Plant Physiology 163: 1047-1058

Reed JW, Nagpal P, Poole DS, Furuya M, Chory J (1993) Mutations in the Gene for the Red Far-Red Light Receptor Phytochrome-B Alter Cell Elongation and Physiological-Responses Throughout Arabidopsis Development. Plant Cell 5: 147-157

Ruttink T, Arend M, Morreel K, Storme V, Rombauts S, Fromm J, Bhalerao RP, Boerjan W, Rohde A (2007) A molecular timetable for apical bud formation and dormancy induction in poplar. Plant Cell 19: 2370-2390

Skinner RH, Simmons SR (1993) Modulation of Leaf Elongation, Tiller Appearance and Tiller Senescence in Spring Barley by Far-Red Light. Plant Cell and Environment 16: 555-562

Smith $\mathbf{H}(2000)$ Phytochromes and light signal perception by plants--an emerging synthesis. Nature 407: 585-591

Smith JE, Jordan PW (1994) Stand Density Effects on Branching in an Annual Legume (SennaObtusifolia). Annals of Botany 74: 17-25

Stafstrom JP, Ripley BD, Devitt ML, Drake B (1998) Dormancy-associated gene expression in pea axillary buds. Planta 205: 547-552

Stamm P, Kumar PP (2010) The phytohormone signal network regulating elongation growth during shade avoidance. J Exp Bot 61: 2889-2903

Takeda T, Suwa Y, Suzuki M, Kitano H, Ueguchi-Tanaka M, Ashikari M, Matsuoka M, Ueguchi C (2003) The OsTB1 gene negatively regulates lateral branching in rice. Plant J 33: 513-520

Tamas IA, Ozbun JL, Wallace DH, Powell LE, Engels CJ (1979) Effect of Fruits on Dormancy and Abscisic-Acid Concentration in the Axillary Buds of Phaseolus-Vulgaris L. Plant Physiology 64: 615-619

Tamura K, Stecher G, Peterson D, Filipski A, Kumar S (2013) MEGA6: Molecular Evolutionary Genetics Analysis Version 6.0. Molecular Biology and Evolution 30: 2725-2729

Tao Y, Ferrer JL, Ljung K, Pojer F, Hong FX, Long JA, Li L, Moreno JE, Bowman ME, Ivans L, Cheng YF, Lim J, Zhao YD, Ballare CL, Sandberg G, Noel JP, Chory J (2008) Rapid synthesis of auxin via a new tryptophan-dependent pathway is required for shade avoidance in plants. Cell 133: 164176

Tatematsu K, Ward S, Leyser O, Kamiya Y, Nambara E (2005) Identification of cis-elements that regulate gene expression during initiation of axillary bud outgrowth in arabidopsis. Plant Physiology 138: 757-766

Thimm O, Blasing O, Gibon Y, Nagel A, Meyer S, Kruger P, Selbig J, Muller LA, Rhee SY, Stitt M (2004) MAPMAN: a user-driven tool to display genomics data sets onto diagrams of metabolic pathways and other biological processes. Plant J 37: 914-939

Thirulogachandar V, Alqudah AM, Koppolu R, Rutten T, Graner A, Hensel G, Kumlehn J, Brautigam A, Sreenivasulu N, Schnurbusch T, KuhImann M (2017) Leaf primordium size specifies leaf width and vein number among row-type classes in barley. Plant J 91: 601-612

Thompson JD, Gibson TJ, Plewniak F, Jeanmougin F, Higgins DG (1997) The CLUSTAL_X windows interface: flexible strategies for multiple sequence alignment aided by quality analysis tools. Nucleic Acids Research 25: 4876-4882

Thompson JD, Higgins DG, Gibson TJ (1994) Clustal-W - Improving the Sensitivity of Progressive Multiple Sequence Alignment through Sequence Weighting, Position-Specific Gap Penalties and Weight Matrix Choice. Nucleic Acids Research 22: 4673-4680

Tian T, Liu Y, Yan HY, You Q, Yi X, Du Z, Xu WY, Su Z (2017) agriGO v2.0: a GO analysis toolkit for the agricultural community, 2017 update. Nucleic Acids Research 45: W122-W129 
Tucic B, Ducic J, Pemac D (2006) Phenotypic responses to early signals of neighbour proximity in Picea omorika, a pioneer conifer tree. Basic and Applied Ecology 7: 443-454

Tucker DJ, Mansfield TA (1971) Effects of light quality on apical dominance in Xanthium strumarium and the associated changes in endogen ous levels of abscisic acid and cytokinins. Planta 102: 140-151

Usadel B, Nagel A, Thimm O, Redestig H, Blaesing OE, Palacios-Rojas N, Selbig J, Hannemann J, Piques MC, Steinhauser D, Scheible WR, Gibon Y, Morcuende R, Weicht D, Meyer S, Stitt M (2005) Extension of the visualization tool MapMan to allow statistical analysis of arrays, display of corresponding genes, and comparison with known responses. Plant Physiol 138: 1195-1204

Wang H, Wang HY (2015) Phytochrome Signaling: Time to Tighten up the Loose Ends. Molecular Plant 8: $540-551$

Wang H, Wu GX, Zhao BB, Wang BB, Lang ZH, Zhang CY, Wang HY (2016) Regulatory modules controlling early shade avoidance response in maize seedlings. Bmc Genomics 17

Wang HW, Chen WX, Eggert K, Charnikhova T, Bouwmeester H, Schweizer P, Hajirezaei MR, Seiler C, Sreenivasulu N, von Wiren N, Kuhlmann M (2018) Abscisic acid influences tillering by modulation of strigolactones in barley. Journal of Experimental Botany 69: 3883-3898

Wei H, Zhao Y, Xie Y, Wang H (2018) Exploiting SPL genes to improve maize plant architecture tailored for high-density planting. J Exp Bot 69: 4675-4688

Whipple C, Kebrom TH, Weber AL, Yang F, Hall D, Meeley R, Schmidt R, Doebley J, Brutnell TP, Jackson DP (2011) grassy tillers1 promotes apical dominance in maize and responds to shade signals in the grasses. Proceedings of the National Academy of Sciences of the United States of America 108: E506-E512

Yao X, Ma H, Wang J, Zhang DB (2007) Genome-wide comparative analysis and expression pattern of TCP gene families in Arabidopsis thaliana and Oryza sativa. Journal of Integrative Plant Biology 49: 885-897

Zadoks JC (1985) Citation Classic - a Decimal Code for the Growth-Stages of Cereals. Current Contents/Agriculture Biology \& Environmental Sciences: 14-14

Zimmermann P, Hirsch-Hoffmann M, Hennig L, Gruissem W (2004) GENEVESTIGATOR. Arabidopsis microarray database and analysis toolbox. Plant Physiology 136: 2621-2632

\section{Supplemental Information}

Supplemental Figure S1. Flowering in wild type and int-c mutant plants at 15 weeks after germination. Shown are three independent replicates for each.

Supplemental Figure S2. Validation of microarray data by qRT-PCR after decapitation treatment. A mRNA levels of a subset of genes identified as responding to the decapitation treatment both in wildtype and int-c samples. C and D, Pearson's correlations between gene expression levels determined by qRT-PCR and microarray expression profiling for the same genes. Although the correlations of both datasets are high, microarray data underestimate the degree of change. The qRT-PCR and microarray data showed a very high average Pearson correlation coefficient $(0,9107$; confirming the high reliability of the array data.

Supplemental Figure S3. Validation of microarray data by qRT-PCR. A and B, mRNA levels of a subset of genes identified as responding to the shade treatment both in wild-type and int-c samples. C and D, Pearson's correlations between gene expression levels determined by qRT-PCR and microarray expression profiling for the same genes. Although the correlations of both datasets are high, microarray data underestimate the degree of change. The qRT-PCR and microarray data showed a 
837 very high average Pearson correlation coefficient $(0.85$ and 0.81 for the wild type and int-c, respectively; confirming the high reliability of the array data.

\section{Supplemental Figure S4. Selected MAPMAN-based categorization of DEGs}

Supplementary table 1: List of TCP genes and associated gene expression derived from public databases.

Supplementary table 2: List of differential expressed genes (DEGs) for WT vs int-c (Control condition), WT vs int-c (shading condition), WT vs WT shading condition, int-c vs int-c shading condition, WT vs WT decapitation condition. Each with a list of associated direction of change.

849

Supplementary table 3: List of INT-C dependent genes, including comparison of direction after shading and decapitation. 